\title{
Examining the Possible Effects of (Mis) Matches between EFL Teachers' and Students' Perceptions of L2 Writing Assessment on Students' Writing Achievement Scores
}

\author{
Mostafa Tajgozari \\ Shiraz University
}

\begin{abstract}
The present mixed-methods study intended to explore Iranian EFL teachers' and students' perceptions of assessing students' written performance and the effect of any possible (mis)matches on students' achievement. To these aims, a convenient sample of teachers $(\mathrm{N}=5)$ and students $(\mathrm{N}=30)$ from different classes and institutes in Iran was recruited to participate in the study. In the first phase of the study, all of the participants, both teachers and students, were interviewed to determine their perceptions of writing assessment. In the next phase, students were asked to write about a topic and in the last phase, the writings were assessed and scored by both teachers and students. During this phase, teachers and students were asked to think aloud while assessing the writings. Results indicated that a) based on teachers' perceptions, language, punctuation, content, organization, and communicative achievement are important factors in assessing a piece of writing, respectively; b) based on students' perceptions, grammar and spelling are important factors in the assessment of a piece of writing, respectively; c) students' perceptions of writing assessment affected their writing scores. That is, based on their own perceptions of criteria for writing assessment, the students expected to receive higher scores than the ones given by their teachers.
\end{abstract}

Keywords: assessing writing; criteria; institutes; teaching; written performance 